\title{
Os alunos da educação de jovens e adultos como sujeitos participativos da gestão democrática: cruzando olhares
}

\author{
Cláudio Correia de Oliveira Neto (D) @ \\ Universidade Federal do Rio Grande do Norte (UFRN), Brasil
}

Resumo. Governança aplicada à educação é compreendida enquanto às relações interpessoais, relações de poder e processo decisório da comunidade escolar na gestão da educação. Investigamos se os/as estudantes da Educação de Jovens e Adultos (EJA) se veem como sujeitos capazes de participar da gestão democrática da escola. Para isso vamos identificar as visões dos vários sujeitos da EJA (estudantes, professores e gestores) sobre a capacidade dos/das estudantes da EJA participarem da gestão democrática da escola e mapear os espaços de participação destinados aos/ às estudantes de EJA. Optamos por realizar um estudo de caso na Escola Municipal Prefeito Janilson Ferreira, município de São José do Mipibu, Rio Grande do Norte, Brasil. Os resultados apontam para a necessidade de auxiliar a gestão, professores e alunos a alargarem o conceito e a prática participativa, para uma esfera de participação ampla e profunda que alcance os aspectos políticos e sociais, colaborando para lograr êxito em terem suas reivindicações atendidas e fomentar entre eles redes de macroparticipação com força de transformação social.

Palavras-chave: governança; gestão democrática; educação de jovens e adultos

\section{Los alumnos de la educación de jóvenes y adultos como actores participativos en la gestión democrática: un cruce de miradas}

Resumen. Se entiende la gobernanza aplicada a la educación como las relaciones interpersonales, relaciones de poder y un proceso decisivo de la comunidad educativa en la gestión de la educación. Investigamos si los/las estudiantes de la Educación de Jóvenes y Adultos (EJA) se ven como actores capaces de participar en la gestión democrática de la escuela. Para ello, vamos a identificar la visión de los distintos actores de la EJA (alumnos, docentes y gestores) sobre la capacidad de los/las estudiantes de EJA en la participación de la gestión escolar democrática y mapear los espacios de participación destinados a los/ las estudiantes de EJA. Optamos por realizar un estudio de caso en la Escuela Municipal Prefeito Janilson Ferreira, municipio de São José do Mipibu, Rio Grande do Norte, Brasil. Los resultados apuntan a la necesidad de ayudar la gestión, a profesores y alumnos a ampliar el concepto y la práctica participativa a una esfera de participación amplia y profunda que alcance los aspectos políticos y sociales, contribuyendo a que logren sus reivindicaciones y fomenten entre ellos redes de participación a nivel macro que tienen fuerza de transformación social.

Palabras clave: gobernanza; gestión democrática; educación de jóvenes y adultos.

\section{Students of youth and adult education as participative subjects of democratic management: cruising looks}

Abstract. Governance applied to education is understood in terms of interpersonal relationships, power relationships and the decision-making process of the school community in the management of education. We investigate whether the students of Youth and Adult Education (EJA) see themselves as subjects capable of participating in the democratic management of the school. For this, we will identify the views of the various subjects of EJA (students, teachers and managers) on the ability of EJA students to participate in the democratic management of the school and map the spaces of participation destined for EJA students. We chose to conduct a case study at the Municipal School Mayor Janilson Ferreira, municipality of São José do Mipibu, Rio Grande do Norte, Brazil. The results point to the need to help management, teachers and students to broaden the concept and participatory practice, to a sphere of broad and deep participation that reaches the political and social aspects, collaborating to achieve success in having their demands met and fostering among them macroparticipation networks with a force for social transformation.

Keywords: governance; democratic management; youth and adult education 


\section{Introdução}

O conceito de Governança surge no contexto anglo saxão no campo da teoria econômica inicialmente para tratar da gestão de recursos nas mais variadas instituições. Com o passar do tempo o conceito passou a fazer referência a "à análise dos padrões de articulação e cooperação entre os atores e os arranjos institucionais que coordenam os sistemas sociais" (Reis, 2013, p.102). Diversos áreas do conhecimento adotaram e adaptaram o conceito de Governança. No campo da educação ele passa a ser aplicado às relações interpessoais, relações de poder, processo de comunicação e processo decisório da comunidade escolar no processo de gestão da educação. No sistema educacional brasileiro os desafios de uma boa Governança se colocou no período histórico da Redemocratização (1985-1988) que impôs um grande desafio a educação, educar para democracia. Esta demanda se originou dos movimentos sociais da década de 1970 que enfrentaram a Ditadura Civil-Militar, compostos pela sociedade civil e com forte representação das entidades dos profissionais de educação e estudantes.

Toda esta discussão em torno da educação para a democracia reverbera na constituinte de 1987, que dá origem a Constituição Cidadã (1988) e também repercute na Lei de Diretrizes e Bases da Educação Nacional (LDBEN -1996). Uma disputa acirrada no campo ideológico e legislativo se desenrola na disputa por como democratizar a educação e as instituições de ensino. De um lado um projeto herdeiro das lutas sociais das décadas anteriores e do outro um projeto de modernização alinhado com o neoliberalismo em ascensão. 0 resultado do jogo foi uma série de instrumentos legais consensuais sobre a importância de uma gestão democrática das escolas, restritas as da rede pública de ensino, com largas margens para interpretação e nenhum mecanismo concreto de operacionalização da gestão democrática (Nardi,2016).

Tanto a proposta de viés mais popular quanto a de caráter neoliberal possuem um conjunto significativo de aproximações que deixam as disputas num campo muito mais dúbios. Ambos propõem participação popular, descentralização do poder, autonomia e organizações locais de controle. Contudo o modelo neoliberal adota estes princípios a partir da demanda de mercado numa postura de incentivo ao Estado Mínimo e atrelados aos interesses hegemônicos do capital que não possuem compromisso com a transformação popular, mas apenas com pontuais mudanças que auxiliem na permanência do status quo deste grupo. O modelo popular já faz uso desses mesmos mecanismos observando os "princípios do poder do povo, da liberdade e da igualdade dos cidadãos" (Ferreira, 2013). 
A Participação é um fator comum que nos possibilita analisar as diversas realidades institucionais independente de em qual espectro ela esteja (popular ou neoliberal). Obviamente os dois modelos apresentados até aqui possuem propósitos distintos acerca da participação, o neoliberalismo usa a participação como partilha da responsabilidade e o seu viés oposto a usa como redistribuição do poder. Todavia a literatura especializada nos fornece um conjunto teórico generalizante que nos fornece parâmetros de análise considerando tipologia e níveis de participação (Bordenave, 1983).

Concordemos com a literatura quando a mesma afirma que o desejo de participar é inerente ao homem e necessita de condicionantes para o desenvolvimento de seu potencial (Bordenave, 1983), e acrescemos que entre estas condições está o autoconceito produzido pelo sujeito (Solé, 2006). 0 participante precisa ter um autoconceito positivo sobre si e sua capacidade de participar. 0 autoconceito é construído via os discursos produzidos pelo próprio indivíduo e a coletividade que o cerca. Podendo ele ser positivo ou negativo, implicando diretamente na ação do sujeito, uma vez que quando a visão de si é positiva ele se considera apto a participar. Está visão que a pessoa tem de si é retroalimentada pelo conjunto de suas experiências anteriores, ou seja, ao ter seu direito de participação restringida em algum momento ele internaliza/aprende que é apenas aquela a parte que the cabe no processo.

Mediado por estas discussões conceituais nossa proposta é verificar se os/as estudantes da Educação de Jovens e Adultos (EJA) se veem como sujeitos capazes de participar da gestão democrática da escola. Para isso vamos identificar as visões dos vários sujeitos da EJA (estudantes, professores e gestores) sobre a capacidade dos/das estudantes da EJA participarem da gestão democrática da escola e mapear os espaços de participação destinados aos/ às estudantes de EJA.

A pesquisa se dará por meio de entrevista com os gestores, dinâmica para coleta de dado para verificação de autoimagem para as/estudantes da EJA, dinâmica para coletas de dados para verificação de imaginário adaptado aos professores da Escola Municipal Prefeito Janilson Ferreira (EMPJF), município de São José do Mipibu, Rio Grande do Norte, Brasil. Os dados também serão dados via estatísticas fornecidas pelo Instituto Nacional de Estudos e Pesquisas Educacionais Anísio Teixeira (INEP).

Os dados coletados e suas análises estão distribuídos em cinco sessões. As quatro primeiras cuidam de analisar a visão de sujeitos pontuais, respectivamente, a técnica da secretaria municipal de São José de Mipibu, gestores, professores e alunos da EMPJF. E a última sessão destinado a cruzar os olhares destes sujeitos. 


\section{O olhar da Secretaria Municipal de Educação de São José do Mipibu}

\subsection{A rede municipal de São José de Mipibu: Dados e inferências}

A rede municipal de educação de São José de Mipibu conta com 16 escolas, com 10.248 matrículas $^{1}$, distribuídas da Educação Infantil ao Ensino Médio. Cerca 5,28\% das matrículas são no ensino fundamental na modalidade de Educação de Jovens e Adultos, com predomínio de matrícula nas escolas urbanas. Conforme dados do portal "Fora da escola não pode"2 o município tem $91,8 \%$ das crianças e adolescentes matriculados. A maior faixa etária de evasão é a entre 15 e 17 anos que representa 4\% da população jovem. São José do Mipibu segundo informações do Instituto Brasileiro de Geografia e Estatística $^{3}$ (IBGE) tem mais de seis mil analfabetos com mais de 15 anos de idade, o que representa mais de $30 \%$ da população na mesma faixa etária. Confrontando os números de matrículas da EJA municipal com a demanda apontada pelo IBGE e as informações do portal "Fora da escola" fica claro que há uma população que demanda educação mas que não chega a rede municipal de ensino. A partir dessa inferência mediante dados foi realizada a entrevista com a técnica responsável pela EJA no município em estudo.

\subsection{A EJA de São José do Mipibu: entre desafios e resistências}

Em 05 de julho de 2017 uma das coordenadoras da EJA, na cidade de São José de Mipibu/RN, Hércia Dantas dos Santos concedeu a pesquisadores uma entrevista onde traçou o panorama geral da modalidade no município, falando dos desafios enfrentados pela equipe técnica, dos perfis dos gestores, professores e alunos.

No início a coordenadora fez uma breve contextualização sobre a desvalorização na EJA na cidade de São José de Mipibu, ressaltando sobre às gestões anteriores e a atual, ambas sem perspectivas para a EJA. Para a modalidade há quatro coordenadoras, cada uma responsável por um nível. A entrevistada é responsável pelo primeiro segmento que atua com o combate ao analfabetismo. 0 município não conta com nenhum programa próprio para a questão, mas aderiu ao programa federal "Brasil Alfabetizado". A ausência de um programa municipal é vista pela técnica como um indício do desinteresse do poder público local com a EJA. Ao todo o programa conta com 23 turmas abertas. A secretaria municipal de educação é responsável

\footnotetext{
${ }^{1}$ Segundo os dados do Censo Escolar de 2019 disponível no sítio eletrônico do INEP para consulta pública (https://bit.ly/2L8s426).

2 Portal organizado pelo UNICEF dentro da campanha nacional pelo direito à educação (https://bit.ly/2SXI63t).

${ }^{3}$ Dados disponíveis no sítio eletrônico do Ministério Público do Paraná baseado no censo de 2010 (https://bit.ly/2SIkqQb)
} 
por cadastrar e monitorar os "Alfabetizadores Populares" que atuaram junto às turmas do programa. 0 perfil desses "alfabetizadores" são em sua grande maioria universitários, predominantemente dos cursos de pedagogia, que recebem uma bolsa de auxílio para a realização das atividades pedagógicas. Como afirmado anteriormente é a secretaria que deve monitorar as atividades e fornecer a formação continuada, contudo a ausência de recursos financeiros e materiais inviabiliza cumprir com esta obrigação. Não há carros disponíveis para levar as técnicas a campo para avaliarem o andamento das ações e nem verba para dá cursos ou material de formação continuada para os "alfabetizadores populares". Devido a pendências fiscais de gestões anteriores até aquele momento o programa estava suspenso no munícipio. O que para nossa entrevistada era motivo de muita preocupação tendo em vista que o trabalho em seu cotidiano já é precário, e na atual conjuntura nem isto mais. Ela ressaltou a importância do trabalho, principalmente considerando o grande número de analfabetos no município, a coordenadora faz uma observação sobre a situação de alguns da população onde diz: "que em nível de uma cidade metropolitana que infelizmente ainda existe pouco mais que $10.000^{4}$ habitantes analfabetos e sem atendimentos nas escolas na oferta em EJA" e os que se matriculam poucos chegam ao final do período letivo, por diversos motivos segundo sua experiência.

A coordenadora relatou que nos últimos anos está ocorrendo um fenômeno da queda nos números de matrículas, o que levou a proporcional queda no número de escolas que ofertam a modalidade. A principal causa elencada por ela é a violência na cidade, o que faz com que algumas escolas fecharem as turmas noturnas e alunos da EJA daquele turno se evadirem. Com isso apenas quatro escolas ofertam a EJA, sendo duas no período noturno, a escola municipal CERU, localizada na comunidade Laranjeiras do Abdias, e a Severino Bezerra de Melo no centro de São José de Mipibu, ambas com anos iniciais e finais do fundamental. As demais citadas são a escola municipal prefeito Janilson Ferreira localizada na comunidade Arenã e a Clóris Trigueiro Peixoto encontrada no Pau Brasil que oferta o período vespertino na EJA com ensino de fundamental fase final.

Outro desafio apontado pela coordenadora é a falta de compromisso dos professores envolvidos com a EJA no município. Segundo ela isto ocorre por causa do perfil desses profissionais, eles não são qualificados para a modalidade, encaram a EJA como complemento da carga horária do ensino regular, e não possuem nenhuma identificação com o alunado. Isso faz com que estes professores tratem as questões e as formações continuadas da EJA como coisas menores. Somasse a isso a peculiaridade de que é comum na alfabetização.

${ }^{4}$ A coordenadora levou em consideração a população que está no período de 
EJA do município as turmas serem formadas na verdade por indivíduos que têm uma grande taxa de distorção idade-série. Ao invés de se desenvolver um trabalho de diagnóstico e intervenção das deficiências de aprendizagem, a equipe pedagógica acha melhor criar uma turma de EJA para acelerar a escolarização. Como estas turmas estão inseridas em escolas predominantemente regulares e não são acompanhados por especialistas acaba ocorrendo o processo de regularização da EJA, ou seja, é como se ela fosse uma modalidade regular só que menor e em mais curto espaço de tempo. Falta por parte dos docentes o entendimento de que:

Destaca-se também que devemos atentar para que o currículo escolar da EJA não reproduza simplesmente os currículos, métodos e materiais da educação infantojuvenil. Ele deve se apresentar mais flexível e menos compartimentalizado, reconhecendo processos de aprendizagem informais e formais, de modo que os estudantes possam obter novas aprendizagens e autodeterminem suas biografias educativas. (Freitas, 2013, p.213)

A entrevistada afirmou que esse conjunto de problemas apresentados até aqui são os motivos recorrentes que trazem alunos da EJA a secretaria municipal, mais especificamente a ausência de oferta de vagas no turno noturno próximo a residência dos educandos. A própria coordenadora reconhece que a negativa das vagas é uma violação ao direito constitucional à educação, contudo sem os condicionantes adequados nada pode fazer além de ouvir e encaminhar as reclamações. Ela aponta ainda que acha bom que o estudante da EJA procure a secretaria para exigir seus direitos e pressionar o poder local a agir. Relatou também que alguns professores da modalidade também a procuram para melhorarem suas práticas pedagógicas. A coordenadora nos contou e mostrou um vasto material disponibilizado pelo Ministério da Educação para as escolas da EJA e que nunca foram lá buscar. 0 material é um pequeno acervo para a biblioteca escolar com livros paradidáticos destinados a professores e alunos.

Ao ser questionada sobre a gestão escolar democrática no município ela fez menção a ser uma utopia, explicando que as decisões ainda são centralizadas pelo governo local que não dá autonomia administrativas as unidades de ensino. Afirmou ela que sem a vivência democrática na escola a educação nunca cumpriria o seu papel de formar para a Democracia. Além de dizer que o regime que se encontra nas escolas não é o democrático mas o burocrático, o gerencialista ${ }^{5}$. Ela crer que os alunos da EJA sejam capazes de participar da gestão democrática das escolas, mas com limitações por causa da visão deles ainda ser muito parecida com a dos alunos do ensino regular. A própria coordenadora afirma que o perfil do alunado da EJA não

${ }^{5}$ Conceito empregado pela própria entrevistada que possui curso de pedagogia com habilitação em Administração Escolar 
difere do perfil dos alunos regulares, possivelmente esta afirmação se relaciona ao fato supracitado da distorção idade-série e a opção por inserir alunos do regular na EJA.

Em síntese a representante da secretaria municipal de São José de Mipibu entende que não há um gestão democrática plena no município, considerando principalmente os aspectos administrativos, que os alunos da EJA embora tenham potencialidade para participarem da gestão ainda são muito imaturos e que os professores não possuem compromisso para com a modalidade e recusam o apoio fornecido pelo governo local.

\section{0 olhar da gestão escolar}

\subsection{Caracterização do campo de pesquisa}

Considerada escola rural, a Escola Municipal Prefeito Janilson Ferreira, foi fundada no ano de 1991, no mandato do prefeito Janilson Ferreira, nos primeiros anos da década de 1990, está situada na localidade do Arenã, zona rural do município de São José de Mipibu-Rio Grande do Norte, Brasil.

0 estabelecimento de ensino foi criado pelo ato $n^{\circ} 478$ de 20 de março de 1991, tendo seu funcionamento autorizado pelo ato $n^{\circ} 03$ de 28 de abril de 2003. A referida escola funciona em dois turnos: matutino (07h00min às $11 \mathrm{~h} 20 \mathrm{~min}$ ) e vespertino (13h00min às $17 \mathrm{~h} 10 \mathrm{~min}$.

Atualmente a escola dispõe de uma infraestrutura de aproximadamente $50.000^{2}$ (cinquenta mil) metros quadrados, dispostos por duas estruturas: uma mais antiga com 09 salas de aulas, 01 diretoria, 03 banheiros e 01 cozinha. Na parte nova da estrutura que ainda está em processo de finalização, temos: 06 salas de aulas, 02 banheiros. A reforma ocorre desde 2014 com intervalos entre as obras, o motivo da extensão de tempo é que algumas partes da obra foram mal feitas o que obrigou a refazer os serviços com melhor qualidade e acabamento.

A Escola atende a aproximadamente 400 alunos onde funciona no turno matutino o ensino fundamental anos iniciais da modalidade regular e no turno vespertino os anos finais do ensino fundamental na modalidade regular e a Educação de Jovens e Adultos-EJA. A mesma conta com uma média de 40 funcionários, divididos entre Professores e Agentes Educacionais I e II. 


\subsection{Responsabilidade e poder: uma difícil divisão}

Maria das Neves Silva de Assis está no segundo ano de seu mandato na EMPFF Ela já tem oito anos de experiência como gestora em outras instituições escolares da rede municipal. A gestora entrevista chegou ao cargo por meio de eleições escolares ${ }^{6}$. E garante que a escola vive a gestão democrática. Mas a mesma ressalta que as tomadas de decisões são tomadas via conselhos, porém a reorganização devido à recente pose e a reforma da escola tem impedido as reuniões regulares do conselho, que como bem frisou a entrevista, precisam ser previamente agendadas com muita antecedência. 0 que podemos inferir que na prática o cotidiano da escola é decidido pelo grupo gestor (gestora, vice gestor e coordenadora pedagógica).

A fala da gestora ainda nos leva a notar uma ideia de participação mais vinculada a modalidade dirigida, que é quando um dos membros provoca os demais a participarem, geralmente usando instrumentos legais ou burocráticos para isso, para decidir ou apenas referendar uma decisão já tomada pelos graus mais altos da hierarquia institucional (Bordenave, 1983). A participação acaba ficando mais a nível de transparência da informação, que é uma característica democrática, mas não suficiente para uma participação democrática plena (Bordenave, 1983).

É interessante notar no tom da entrevistada um ar de preocupação tipicamente neoliberal (Lopes \& Castro, 2012). Os conselhos servem mais a um propósito de partilha da responsabilidade, devido ao medo de uma punição legal ou administrativa por mau uso dos recursos públicos. A gestão então dilui seu papel de responsável em eventual caso de infração com os demais membros da comunidade escolar. Dividisse a responsabilidade, mas não o poder.

Para a gestora o grupo mais participativo da escola é a do turno matutino, onde toda a comunidade escolar é mais ativa. Vale ressaltar que o matutino atende criança dos 7 aos 12 anos, com professores polivalentes não horistas, e que pela faixa etária dos estudantes exige maior presença dos responsáveis que supomos vão levar e buscar os estudantes na escola. Todos estes fatores descritos são condicionantes que facilitam a participação da comunidade. $O$ encontro no portão da escola ajuda os responsáveis a formarem redes de sociabilização e mobilização. Os professores polivalentes responsáveis por acompanhar diariamente os alunos contribuem para estreitar os laços escola-família. Como os alunos ainda são muito novos não expressão satisfatoriamente sua vontade ao ponto de terem ou reivindicarem poder de

\footnotetext{
${ }^{6}$ Relatos dos professores afirmam que a eleição foi acirrada e sofreu interferência da secretaria municipal. A gestora eleita tem afinidades políticas com o atual governo local.
} 
decisão. Tudo isso colabora para a participação e para amenizar conflitos e disputas de poder no interior da escola. Não por acaso a gestora indicou este turno como o mais participativo, uma vez que ele tem boas condições para o exercício democrático.

A escola ainda não conta com um espaço físico que possibilite a reunião de toda a comunidade para participar das atividades. De maneira provisória se usa o galpão da escola, que não comporta a todos. 0 espaço físico foi sempre posto como um obstáculo para a gestão democrática plena na escola. Contudo ele não é o único. A gestão reclama das dificuldades de organizar administrativamente a escola, até o momento não há regimento interno, Projeto Político Pedagógico (PPP) e demais instrumentos administrativos. A organização que se tem é o que já vem pré-moldado pela própria secretaria de educação. Este é o caso por exemplo do próprio PPP da EJA que foi formulado pela secretaria e que a escola ainda não adaptou a suas especificidades. Talvez a ausência de uma coordenadora pedagógica para o turno vespertino, onde está a EJA, seja um importante fator para a desordem. A escola conta com apenas uma coordenadora que é do quadro de funcionários matutino, mas que "quebra um galho" no vespertino resolvendo apenas assuntos de ordem burocráticas como, por exemplo, cadernetas.

Ao tratar do perfil dos alunos da EJA a gestora afirmou que a turma é formada "de alunos que já vem de muitas reprovações e se encontra fora da faixa etária, do $6^{\circ}$ e $7^{\circ}$ ano e ainda pela evasão escolar das mesmas séries." Fala que confirma o que já foi apresentado pela técnica da secretaria. E aqui ambas concordam que por este perfil a participação dos alunos da EJA é muito limitada devido a sua imaturidade. A diretora ainda acrescenta o fator timidez como um impedimento a maior participação dos estudantes. Ela afirma pensar estratégias para estimular a participação, o que confirma a hipótese de que a mesma, crer em uma participação dirigida. Embora fale no desejo de estimular a participação não há nenhuma ação neste sentido, apenas palavras.

No encerramento da entrevista a equipe deixou a colaboradora a vontade para falar o que desejasse. As falas fruto deste momento foram as seguintes: "Queria demais que os jovens conseguissem e tivessem alguém para despertar nossos alunos para um futuro melhor e uma educação de qualidade para todos". E prossegue: "que os jovens tivessem um incentivo maior para melhor aprender". A fala da educadora é interessante pois revela um autoconceito negativo em relação a si, ela não se percebe enquanto a que "despertar nossos alunos para um futuro melhor" ou a que incentiva os alunos. Isto revela uma visão de gestão escolar atrelada mais a pura a administração escolar e desalinhada com o novo paradigma do gestor escolar enquanto promotor da inovação pedagógica e da inclusão (Castro, Brito, Dos 
Santos, Varela, 2015; Salvador, Moura, Silva, Maia, 2006; Nuñes \& Santos, 2012). Na ótica do pragmatismo o diretor é a figura central que busca a máxima eficiência administrativa e pedagógica. De maneira centralizadora, descontextualizada e fria o diretor escolar formularia os conceitos norteadores da escola e ao professor caberia apenas executá-los. A burocratização da educação permite uma comodidade ao definir atores e papéis sociais, mas perde ao tornar a escola um espaço inflexível (Tavares, Azevedo, Morais, 2014). 0 novo paradigma precisa ser construído levando em consideração a necessidade de uma escola mais aberta à diversidade, mais maleável a sua clientela e com maior eficácia na atividade fim de formação cidadã (Tavares et al., 2014; Castro et al., 2015). A gestão escolar deve estimular a comunidade a participar das decisões coletivamente (Castro et al., 2015).

Em suma a representante da gestão escolar entende a gestão democrática mais nos aspectos administrativos, pautados na transparência da informação com a divisão dos ônus e riscos, mas com poder ainda centralizado e dependente do poder local. Assim como a técnica da secretaria, a gestora acredita que os alunos da EJA embora tenham potencialidade para participarem da gestão ainda são muito imaturos.

\section{Os olhares dos professores}

Devido o pouco tempo disponível e a quantidade de professores, optamos por usar a técnica de roda de conversa para entendermos na prática como os professores percebem a EJA na escola e como compreendem a questão da participação no contexto escolar. Como o dia da visita era de prova, os professores foram sendo introduzidos na conversa a medida em que chegavam das aplicações das avaliações. Ao todo foram cinco educadores que participaram da roda.

O perfil dos entrevistados é o oposto do que descrito pela técnica da secretaria. Todos os presentes afirmaram ter capacitação para atuarem na EJA e terem uma profunda identidade com a modalidade. A maioria tem anos de experiência com a EJA e se sentem realizados na sua prática.

Ao relatarem os desafios durante as suas trajetórias na EJA os mais ressaltados foram: ameaças, desinteresse dos alunos, falta de livro didático adequado para os alunos dessa modalidade e falta de apoio efetivo dos órgãos superiores que promovem a educação do município. 
0 grupo de professores deixou claro que a gestão escolar tem um olhar cuidadoso para esses alunos que frequentam a EJA e que a escola já enfrentou vários problemas que ocasionaram na evasão de alunos como, por exemplo, a violência dentro e fora da escola, mas que atualmente a escola passa por um bom momento e que a evasão hoje se restringe a casos isolados.

Diante da efetivação da participação e permanência dos alunos da EJA, os professores têm proporcionado aos alunos momentos de valorização do saber do aluno, dinamizando as aulas no intuito de torná-los mais participativos e envolvidos com sua própria aprendizagem. Os professores se preocupam em dar sentido a aprendizagem e compreendem que:

A ideia de grade curricular deve ser superada, assim como o programa de conteúdos definidos pelo livro didático. A proposta é que se pense os conteúdos baseados na provisoriedade do conhecimento, isto é, um conhecimento que nunca terá um estado acabado. Para isso, é necessário uma relação dialógica, onde os significados são compartilhados por todos. $O$ processo é a categoria fundamental para a construção da proposta curricular devido ao caráter dinâmico e cultural contido nessa palavra. A ideia de processo, segundo a proposta, justifica-se pelo fato de que toda aprendizagem é um processo cultural que envolve muito mais que apenas a dimensão intelectual do indivíduo. A escola é descrita como um espaço sociocultural e uma concepção estreita de currículo não dá conta da totalidade da riqueza cultural presente no cotidiano. A proposta curricular deve ter os processos culturais como eixos norteadores. (Eugênio, 2004, p.102).

Para se efetivar um currículo mais adequado a EJA é preciso profissionais mais capacitados e sensíveis:

Pensar em um modelo mais flexível de escola, conectado com a vida. Além disso, investir na formação docente, com mais disciplinas obrigatórias e optativas na graduação. Afinal, o papel desses professores não é preparar os estudantes para o futuro, como ocorre com as crianças, mas ter um olhar mais sensível a tudo que é relevante para esses jovens e adultos, da saúde à religiosidade. (Di Pierro apud Fraidenraich, 2010. p.3).

Os professores presentes na roda de conversa nos revelaram que não há uma atuação efetiva da secretaria de educação no sentido de promover a valorização dessa modalidade de ensino, e que todo trabalho desenvolvido com esses alunos parte da vontade dos próprios professores em proporcionar situações prazerosas dentro e fora da escola. Eles sentem uma necessidade visível de oportunizar aos educandos momentos extra escolares na tentativa de dar mais concretude a certos conteúdos ministrados em sala de aula, mas esbarram na falta apoio logístico por parte da secretaria de educação para realização dessas aulas e no entendimento que a gestão escolar e municipal 
de aula, para as autoridades, segundo os professores, a aula só é entendida pelas hierarquias mais altas quando o aluno está dentro da sala de aula, sentados e escrevendo.

Alguns professores frisaram que uma gestão escolar mais enérgica conseguiria suprir parte da demanda, fazendo referência a gestão anterior ao qual o professor comentador fazia parte. De forma indireta ficou subentendido que o fato da atual gestão ter afinidades políticas com o prefeito a impede de enfrentar a secretaria e trazer recursos para a escola. Houve um esforço por parte dos professores de construir um discurso que favorece a gestão anterior. Em contrapartida houve um esforço da gestora em exercício de produzir um contra discurso e responsabilizar os seus antecessores pela desordem administrativa encontrada.

Mesmo com ideias tão vanguardistas em nenhum momento os professores cogitaram uma elaboração curricular em conjunto com o aluno. Vilar e Anjos (2014) apontam que os alunos da EJA devem assumir um protagonismo na elaboração curricular. As autoras defendem que o acúmulo de experiências deste grupo social os permite expressar claramente o que desejam. Cabe então a escola cartografar esses desejos de aprendizagem e incorporá-los ao currículo formal e real. Isso não significa que será a vontade dos alunos que imperará no currículo, mas que será um componente dele e até um atrativo ou ponto de partida para isso. Então ao invés do livro didático construir o currículo a partir dos referenciais teóricos deveria também convidar os alunos a construírem em coletivo, caso os alunos não consigam expressar adequadamente seu desejo, a equipe deve buscar meio de auxiliar nesta expressão da vontade.

Como vimos à equipe docente apresenta um notório desejo de transformação do ensino na escola, mas que infelizmente enfrentam obstáculos que dificultam a realização de ações pensadas para melhoria da qualidade do ensino ofertado aos jovens e adultos. As falas e ações dos professores apontam para uma compreensão de participação mais próxima de uma participação concedida, aquela que é partilhada com o subordinado e é legítimo para todos os níveis hierárquicos. E aprofundam os níveis de participação para além da informativa, alcançando patamares de consulta obrigatória sem contudo chegar ao grau de autogestão (Bordenaves, 1983). Mas a participação concedida é uma espada de dois gumes, tem potencial para fomentar a participação plena e também para gerar um simulacro de participação uma vez que embora haja consulta obrigatória não serão os participantes a elencar as opções. 


\section{Os olhares dos alunos}

\subsection{Caracterização dos alunos}

A única turma de EJA da escola tem matriculados 19 alunos, 15 frequentam regularmente, apenas um se recusou a participar da pesquisa, contudo respondeu oralmente ${ }^{7}$. A faixa etária deles é de 16 até 21 anos, majoritariamente masculino, com 3 alunos trabalhadores e a maioria provenientes de família de pequenos agricultores rurais. Para captar 0 autoconceito necessário para anal isar o olhar do aluno adotamos um questionário composto de 10 frases incompletas que eles preencheram livremente. Como o nível de dispersão estava alto, uma vez que as aulas já haviam se encerrado e tinham acabado de realizar duas provas, a equipe optou por ditar as frases e os estudantes apenas registrarem as respostas em seus cadernos. Os dados coletados foram sistematizados na tabela abaixo:

\begin{tabular}{|c|c|c|}
\hline Frase & Complemento & $\mathrm{N}^{\circ}$ de repetições \\
\hline \multirow{2}{*}{$\begin{array}{l}\text { 1. Na minha escola quem toma as } \\
\text { decisões é/são }\end{array}$} & A diretora & 14 \\
\hline & Os professores & 18 \\
\hline \multirow[t]{2}{*}{ 2. Na escola eu decido sobre } & Estudar & 12 \\
\hline & O meu futuro & 2 \\
\hline \multirow[t]{5}{*}{ 3. Eu participo da escola } & Atividades & 1 \\
\hline & Aprendendo & 3 \\
\hline & Sim & 8 \\
\hline & Estudando & 1 \\
\hline & UFRN & 1 \\
\hline \multirow[t]{4}{*}{ 4. Eu participo da escola quando } & Tem festa & 1 \\
\hline & Eu quiser & 5 \\
\hline & Todo dia & 4 \\
\hline & Tem aula & 4 \\
\hline \multirow{2}{*}{$\begin{array}{l}\text { 5. Os estudantes participam da es- } \\
\text { cola }\end{array}$} & Estudando & 13 \\
\hline & Quando os professores querem & 1 \\
\hline \multirow{5}{*}{$\begin{array}{l}\text { 6. Os estudantes participam da esco- } \\
\text { la quando }\end{array}$} & Tem jogos & 3 \\
\hline & Tem festa & 6 \\
\hline & Todo dia & 2 \\
\hline & Tem aula & 2 \\
\hline & Querem & 1 \\
\hline \multirow[t]{4}{*}{ 7. Todos da escola se reúnem para } & Passeio & 7 \\
\hline & Reunião & 2 \\
\hline & Estudar & 4 \\
\hline & Ato solidário & 1 \\
\hline
\end{tabular}

${ }^{7}$ Como não houve registro da exposição oral do aluno ele não será contabilizado.

8 O participante incluiu direção e professores em sua resposta, contabilizando assim em ambos as opções 


\begin{tabular}{llc}
\hline \multicolumn{1}{c}{ Frase } & \multicolumn{1}{c}{ Complemento } & $N^{\circ}$ de repetições \\
\hline \multirow{3}{*}{ 8. Todos da escola se reúnem na/no } & Secretaria & 1 \\
\cline { 2 - 3 } & Escola & 12 \\
\cline { 2 - 3 } & Rua & 1 \\
\hline 9. Todos da escola se reúnem quando & Recreio/lanche/Festa/Evento & 6 \\
\cline { 2 - 3 } & Aula & 1 \\
\cline { 2 - 3 } & Prova & 5 \\
\cline { 2 - 3 } & Reunião & 2 \\
\hline \multirow{2}{*}{ 10. A escola deve melhorar em } & Educação & 4 \\
& Tudo & 7 \\
\cline { 2 - 3 } & Esporte & 1 \\
\cline { 2 - 3 } & Transporte & 1 \\
\cline { 2 - 3 } & Infraestrutura & 1 \\
\hline
\end{tabular}

A tabulação dos dados mostra que os estudantes têm uma visão centralizadora das tomadas de decisões, vide que 100\% dos mesmos indicaram a diretora como a responsável por decidir. Isto está atrelada a experiência que eles vivenciam no cotidiano, como apontamos ao analisar a entrevista da gestora que na prática concentra o poder. Interessante observar que em apenas uma das respostas cogitou o poder ser partilhado entre a gestão e os professores. É possível que a centralização da gestão não permita ao alunado perceber os educadores como detentores de poderes decisórios.

As respostas das questões 2 a 6 revelam uma noção de participação restrita ao processo de aprendizagem de maneira passiva. Em grande medida partilhada também pelos educadores que em sua fala explicitaram a ideia de participação sempre atrelada a ações práticas no processo de aprendizagem, meramente executiva e operatória. Os alunos então dentro dos seus exercícios diário e convívio com a comunidade escolar internalizam o papel de meros executores do processo, numa participação de tipo dirigida, a nível informativo e que perpetua as relações de poder no seio da escola.

A resposta mais recorrente ao quarto item, "eu participo da escola quando eu quiser", elucida uma jogo de poder onde se resiste a participação dirigida, usa a participação voluntária como instrumento de resistência e legitima seu poder de arbítrio diante da imposição. 0 querer neste caso pode ser lido como interesse ou motivação. Solé (2006) nos coloca que a disponibilidade de aprender, aqui adaptada para entender a disponibilidade de participar, está vinculada ao significado atribuído à ação. Mesmo que o aluno tenha um autoconceito positivo de capacidade, ele pode não ver sentido/interesse em participar. 0 condicionamento do querer demonstra isto, consciência da faculdade de escolha sem a motivação de realizar a escolha. 
A resposta destoante do quinto item traz à tona uma ideia interessante, ao afirmar que os alunos participam apenas quando os professores querem é um indicativo de que há a hipótese - e talvez a prática - de que existe momentos em que os professores não querem ou não permitem a participação dos alunos. É comum que os licenciados desejem a participação dos alunos em sala de aula, mas não na escolha do conteúdo ou método avaliativo ou ainda que aceite apenas uma participação condicionada a referendar informações, práticas e rituais de poder. Aqui aparece um fenômeno que tem aproximações com que observamos na gestão, se deseja dividir a responsabilidade sobre a aula/ processo de aprendizagem, mas não o poder sobre ela.

Os item 6,7,8 e 9 apresentam uma característica peculiar, a participação atrelada aos eventos de socialização. Os estudantes da EJA valorizam os momentos de socializar com os colegas. Os eventos são as manifestações materiais do coletivo, e naqueles momentos são onde se pode perceber uma participação em sentido mais amplo, onde os alunos vão a um nível mais profundo da atuação, recebendo muitas vezes funções delegadas pelo poder central que o retira da plateia da observação/informação/referendar e passa ao palco das decisões. Podemos assim dizer que os alunos nos eventos escolares exercem uma microparticipação, conforme explica Bordenave (1983, p.29): "a associação voluntária de duas ou mais pessoas - numa atividade comum na qual elas não pretendem unicamente tirar benefícios pessoais e imediatos". Embora este tipo de participação seja importante e assinale para o próprio desejo humano de participar da coletividade (Bordenave,1983), ele ainda não é o alvo a ser alcançado, mas pode ser o feijão mágico que se joga para alcançar o tesouro celeste.

O último item das frases para serem completadas mostrou a ânsia de ser ouvido dos estudantes, ao chegar na décima sentença a turma entrou em alvoroço, "era tanta coisa que não caberia no papel" afirmou um. Foi muito marcante a diferença de comportamento entre este momento e os anteriores. A maioria dos alunos foi sucinto em suas respostas, outros a detalharam. De modo geral estão descontente com o andamento da escola e aquele foi o momento de expressarem. Os desejos difusos ali manifestos só podem produzir bons frutos em um ambiente democrático que os dote de poder para mudar. 


\section{Cruzando os olhares: que participação é essa?}

Todos os sujeitos investigados convergem para uma ideia de participação vinculada às suas experiências rotineiras, de participação restrita e poder centralizado. As ações se internalizaram ao ponto de não serem questionadas e participar se torna um mero ato executivo vazio de reflexão. Parafraseando a música "A gente se acostuma a muito pouco/A gente fica achando que é o máximo/Liberdade pra escolher a cor da embalagem". Dentro do paradigma neoliberal ao qual a sociedade brasileira está inserida o processo de responsabilização ( Lopes; Castro, 2012) cria um clima de planejamento participativo que como aponta Bordenave (1983) é usado por algumas instâncias como maneira de restringir as ações as microparticipações dando uma "ilusão de participação" política e social. Na verdade aqueles grupos não se articulam em uma macroparticipação que efetive "o processo mediante o qual as diversas camadas sociais têm parte na produção, na gestão e usufruto dos bens de uma sociedade historicamente determinada" (Bordenave,1983, p.34). Nos ritos escolares gestores, professores e alunos aprendem que participar é cumprir com a função ao qual foi designado, mesmo que se quer possua recursos materiais para cumpri-la dignamente. A experiência reforça o autoconceito de que ele é incapaz de decidir (Solé, 2006).

É retirado do horizonte de perspectiva destes grupos que a participação não é o quanto se atua, mas em que nível se atua. A crise da democracia representativa se acha aí, não é suficiente ter parte apenas como eleitor se o mesmo não agir num nível de decidir de fato sobre os rumos do país. Ao não refletir sobre o ato de tomar parte do poder a escola não está cumprindo o papel de educar para a democracia, mas apenas retroalimentando a hegemonia do capital interessado em se perpetuar e barrar as transformações sócias (Lopes \& Castro,2012).

A concentração de poder na mão dos mandatários locais provoca um efeito dominó que engessa a técnica da secretaria, a gestora, os professores e deságua nos estudantes. 0 ônus é repartido como pizza a toda a cadeia de comando, que tem autonomia apenas para obedecer. Congelados cada qual em seu ponto de vista não conseguem formar uma rede que gere oportunidade de uma participação social ampla capaz de transformar a realidade da EJA. A cela da rotina cega os encarcerados que não veem mais do que as próprias grades.

Alia-se a tudo isto algo que a pesquisa de Paro (2012) indica, em geral a comunidade escolar acredita que a capacidade de decisão política é uma atividade de nível superior que só pode ser realizada mediante grande esforço intelectual, o que exigiria um grau elevado de escolaridade. É por isso que a participação dos responsáveis geralmente se restringem a ações 
braçais. Ocorre que a capacidade de decidir politicamente é uma condição ontológica, por isso aplicável a todos os seres humanos. Logo é falacioso afirmar que os alunos não têm capacidade de decidir por serem imaturos. Todas as decisões correm risco de serem as erradas, não importa se tomada aos 8 ou 80 anos, a temporalidade apenas indica um acúmulo de experiência, mas nenhuma certeza absoluta. E a própria democracia só é capaz de se aperfeiçoar em seu exercício.

A democracia só é aprendida ao ser vivenciada. Como um músculo que se fortalece a cada vez que é usado, assim é o regime democrático. Educar para a democracia implica construir ambientes e condicionantes para que todos os envolvidos exerçam seus direitos inalienáveis de arbítrio. A existência democrática é um desafio diário. De nada adianta a cidadania como conhecimento da realidade se não aprendermos a usar nosso poder de alterar a sociedade.

O conteúdo pode ser o mais próximo do contexto social possível dos estudante, como desejam os professores entrevistados, mas se isto não servir para que o aluno se oriente no sentido de ser sujeito transformador de nada adiantou o conteúdo, tornou-se tão inútil e obsoleto quanto os conteúdos criticados pelos professores.

É preciso alargar o conceito e a experiência de participação desses sujeitos de maneira que os mesmos possam caminhar rumo às transformações que desejam, ainda que não seja claro o que se almeja.

\section{Conclusões}

Verificamos em nossos estudos que os alunos da EJA da EMPJF se veem como sujeitos participativos, mas com capacidade limitadas de participar da gestão democrática da escola. Isto ocorre porque os mesmos entendem que a participação é restrita às ações pedagógicas a eles designados dentro da tradição escolar. A literatura aponta que os motivos que levam a essa visão de participação tem relação como o mito da decisão política ser privilégio de uma elite intelectual (Paro, 2012), a prática cotidiana reforça a participação restrita e a indisponibilidade de participar (Solé, 2006), a própria estrutura do sistema neoliberal distorce e restringe a noção de participação (Lopes \& Castro, 2012; Tavares et al., 2014).

Técnicos educacionais, professores e gestores atribuem a imaturidade dos alunos a pouca capacidade ou incapacidade dos estudantes de participarem da gestão. Os profissionais porém desconsideram que a faculdade 
humana de participar é inerente ao homem e que precisa ser desenvolvida sua potencialidade mediante estímulo. Além de não perceberem que ao não construírem possibilidades de exercício democrático estão se afastando do propósito de educar para a democracia.

Ao mapear os espaços de participação destinados aos estudantes da EJA detectamos que ele ocorre principalmente nos eventos culturais da escola que fomenta uma microparticipação pontual no aspecto cultural e que pode ser germinal para uma ampliação em escala mais abrangente de atuação.

Nossa pesquisa aponta para a necessidade de auxiliar a gestão, professores e alunos a alargarem o conceito e a prática participativa, saindo do pragmatismo imediatista da microparticipação em que se encontra para uma esfera de participação ampla e profunda que alcance os aspectos políticos e sociais, colaborando para lograr êxito em terem suas reivindicações atendidas. Também precisamos fomentar entre eles redes de macroparticipação com força de transformação social. Um grande desafio que se apresenta é criar práticas que possibilitem modificar o autoconceito existente nos sujeitos estudados de maneira a construir sentido/interesse que os motive a ação de maneira crítica, reflexiva e verdadeiramente democrática.

\section{Referências bibliográficas}

Bordenave, J. E. D. (1983). O que é participação. São Paulo: Brasiliense.

Castro, A.B.C., Brito, L.M.P., Dos Santos, R.S. \& Varela, J.H. de S. (2015). O planejamento estratégico como ferramenta para a gestão escolar: um estudo de caso em uma instituição de ensino filantrópica da Bahia/BA. Holos, 2, 195-211.

Eugênio, B. G. (2004). O currículo na Educação de Jovens e Adultos: entre o formal e o cotidiano numa escola municipal em Belo Horizonte. Dissertação, Pontifícia Universidade Católica de Minas Gerais: Belo Horizonte, MG, Brasil.

Ferreira, N. S. C. (2013). Diversidade e democracia: o nosso compromisso hoje. Revista Retratos da Escola, 7(13), 305-318.

Fraidenraich, V. (2017). A EJA em segundo plano. Recuperado de https://bit.ly/34pdLiv

Freitas, A. V. (2017). Reflexões sobre o currículo da EJA na perspectiva da Educação Matemática. Recuperado de https://bit.ly/2yJupxG

Jesus, A. R. de (2001). Currículo e Educação: conceito e questões no contexto educacional. Dissertação, Universidade Federal de Sergipe, Aracaju, SE, Brasil.

Lázaro, A. L. de F. (2013). A diversidade, a diferença e a experiência da Secad. Revista Retratos da Escola, 7(13), 265-276. 
Lopes, M. D. O. \& Castro, A. M. D. A. (2012). Modernização administrativa: repercussões na gestão educacional. Política Educacional: contextos e perspectivas da educação brasileira. Brasília: Liber Livro.

Nardi, E. L. (2016). Gestão democrática na educação básica Delineamentos da matéria no pós-LDB. Revista Retratos da Escola, 10(19), 477-492.

Nuñes, I. B. \& Santos, F.A.A. (2012). O professor e a formação docente: a criatividade e as crenças educativas onde estão? Holos, 2, 148-165.

Paro, V. H. (2012). Gestão democrática da escola pública. 3. ed. São Paulo: Ática.

Reis, I. (2013). Governança e regulação na educação: perspectivas e conceitos. Revista Educação, Sociedade \& Culturas, 39, 101-118.

Salvador, D.S.C. de O., Moura, D.H. de, Silva, J.A. de A. \& Maia, S.F. (2006). Processo educacional inclusivo: das discussões teóricas à a necessidade de prática. Holos. 22, 11-23.

Solé, I. (2006). Disponibilidade para a aprendizagem e o sentido da aprendizagem. In: Cool, C. 0 Construtivismo na sala de aula. 6 ed. São Paulo: Ática.

Tavares, A.M.B.N., Azevedo, M.A., Morais, P.S. (2014). A administração burocrática e sua repercussão na gestão escolar. Holos, 2, 154-162.

Vilar, J. C. \& Anjos, I. R. S. dos (2014). Currículos e práticas pedagógicas na educação de jovens e adultos. Espaço do Currículo, 7(1), 86-96. 